\section{Prevalence of toxoplasmosis, rubella, cytomegalovirus, and herpes (TORCH) infections among women attending the antenatal care clinic, maternity hospital in Abha, Southwestern Saudi Arabia}

\author{
Ahmed M. Al-Hakami, MSc, PhD, Esther Paul, MBBS, MD, \\ Faten Al-Abed, MBBS, PhD, Ahmad A. Alzoani, MBBS, SBPed, \\ Ayed A. Shati, MBBS, SBPed, Mohammad I. Assiri, MBBS, \\ Asim A. Qasim, MBBS, Fatima Riaz, MBBS, FCPS, \\ Riyad A. Moosa, BSc, MSc, \\ Harish C. Chandramoorthy, PhD, FICS.
}

\section{ABSTRACT}

Objectives: To investigate the presence of toxoplasmosis, rubella, cytomegalovirus, and herpes (TORCH) infections in women attending at the antenatal care clinic in Abha, Kingdom of Saudi Arabia (KSA).

Methods: A total of 190 blood samples were collected from Abha maternity hospital in Aseer region, KSA, from February 2018 to May 2019 and screened with the TORCH panel (toxoplasmagondii [ $\operatorname{IgG} / \operatorname{IgM}]$, cytomegalovirus [CMV] [IgG/IgM], rubella [IgG/ $\operatorname{IgM}]$, and herpes simplex type 1 and 2 [IgG/IgM]).

Results: The mean age was $31.42 \pm 6.514$ years and gestational age was $32.48 \pm 6.168$ weeks. Serum IgG was positive for Toxoplasma gondii (T. gondii) (27.4\%), herpes simplex type 1 (HSV-1) (94.7\%), herpes simplex type 2 (HSV-2) (0.5\%), CMV (100\%), and rubella $(88.9 \%)$. Serum IgM was positive only for CMV (9.5\%). Though, there was an association between abortions from previous pregnancies (26.5\%), intrauterine death $(5.8 \%)$, premature labor (3.2\%), microcephaly (1.6\%), other congenital diseases $(1.6 \%)$ and low birth weight $(0.5 \%)$ with current IgG positivity for TORCH infections, the results were not statistically significant.

Conclusion: Seropositivity for IgG antibodies correlate with TORCH-associated pregnancy complications in Abha, KSA; however, IgM positive CMV pregnant cases warrant further systematic investigation to understand the implications of CMV on outcomes during pregnancy.

Keywords: toxoplasmosis, rubella virus, cytomegalovirus, herpes simplex virus, TORCH

Saudi Med J 2020; Vol. 41 (7): 757-762 doi: 10.15537/smj.2020.7.25121
Toxoplasmosis, rubella, cytomegalovirus, and herpes (TORCH) represents a group of pathogens, namely Toxoplasma gondii ( $T$. gondii), rubella virus, Cytomegalovirus (CMV), and herpes simplex virus (type 1 [HSV-1] and type 2 [HSV-2]), which are the main causative factors for congenital infection, and anomalies in the fetus and new-born, and for abortion (10-15\%). ${ }^{1}$ Research shows that TORCH infections cause high mortality and morbidity in developing countries, and the prevalence of these infections varies between countries. $^{2}$

The Middle East, South-East Asia, Latin America, and Africa have reported a high prevalence of T. gondii infections. ${ }^{1,3}$ Nearly 40,000 women are infected with CMV annually in the United States and Europe, with $20 \%$ of infants born to CMV-infected females acquiring neurological deficits and hearing loss., ${ }^{4,5}$ Rubella is acquired by $30-40 \%$ of fetuses in the first trimester of pregnancy. The maternal symptoms of rubella infection include lymphadenopathy, arthralgia, fever, malaise, conjunctivitis, encephalitis, and hemorrhagic complications. Hearing loss, mental retardation, blindness, and neurological deficits with widespread infection to the brain, lungs, and liver are common manifestations of toxoplasmosis, rubella virus, and CMV among newborns. Infection with either HSV-1 or 2 in an antenatal woman can cause premature labor, abortion, as well as congenital and neonatal herpes. Globally, approximately 3.7 billion people below 50 years of age (67\%) are infected with HSV-1, and 417 million people between $15-49$ years of age (11\%) have HSV-2 infection. ${ }^{6,7}$

Few studies on TORCH infections have been carried out in the Kingdom of Saudi Arabia (KSA). In 2002, one study conducted on pregnant women in Makkah, $\mathrm{KSA}$, reported $\mathrm{IgG}$ antibodies of approximately $35.6 \%$ T. gondii, 92.1\% CMV, 93.3\% rubella, 90.9\% HSV-1 and $27.1 \% \mathrm{HSV}-2 .{ }^{6}$ Another study from Hail, KSA, reported an overall seroprevalence of TORCH infections among pregnant women to be $13 \%$ with $T$. gondii IgG at $12 \%$, T. gondii IgM at 19\%, rubella IgG at 14\%, rubella IgM at $13.6 \%$, and CMV IgG at $13.65 \% .^{8}$ Although isolated studies on CMV have been carried out in the Jizan and Aseer regions reporting nearly 93\% CMV seropositivity among 89 pregnant women, the overall TORCH infection burden is not available for these

Disclosure. Authors have no conflict of interests, and the work was not supported or funded by any drug company. 
regions of KSA. ${ }^{9}$ Thus, the present study has attempted to investigate the presence of TORCH infections among the antenatal women in the southern part of KSA and the relation between TORCH infections and pregnancy-related complications.

Methods. A cross-sectional study was conducted to investigate the frequency of TORCH infections at the maternity hospital in the Aseer region, KSA, between February 2018 and May 2019. A simple random sampling technique was used to collect a sample size of 190 pregnant females. The inclusion criteria included all the multigravida antenatal patients willing to participate in the research. The exclusion criteria for the study included primi gravida patients, patients with any systemic illness, and pregnant women with a family history of any congenital disease.

Sample collection. Blood samples $(5-10 \mathrm{ml})$ and clinical data was collected from pregnant females who came for a routine antenatal check-up after informed verbal and written consent and as per inclusion and exclusion criteria. A detailed history of previous pregnancy outcomes, such as premature labor, low birth weight, microcephaly, intrauterine death (IUD), and other congenital anomalies were recorded. Briefly, serum was separated by centrifuging at 2200-2500 RPM for 10 minutes. The separated serum was stored in aliquots and frozen until tested.

Immunoglobulin $G$ and IgM screening for TORCH infections. The serum samples were screened for CMV IgG and IgM antibodies, rubella IgM antibodies, T. gondii IgG antibodies, HSV-1 and 2 IgG and IgM antibodies using commercially available indirect ELISA kits (Human Diagnostics, Wiesbaden, Germany/ United Diagnostics, KSA/Vircell Microbiologists, Granada, Spain) as per manufacturers' instructions. The serum samples were also screened for rubella IgG and T. gondii IgM antibodies using commercially available capture ELISA kits (United Diagnostics, Dammam, KSA/Human Diagnostics, Wiesbaden, Germany) as per manufacturers' instructions.

Statistical analysis. In this prospective study, we have gathered the data from purposely constructed questionnaire, coded data was entered in the Statistical Package for Social Sciences (SPSS) Version 22 (IBM Corp., Armonk, NY, USA) for analysis along with the results of TORCH IgG and IgM enzyme-linked immunosorbent assay (ELISA). Descriptive statistics $(M e a n \pm S D$, frequencies and percentages were computed). While performing Univariate analysis different statistical tests were used to measure the degree of association between variables of interest. Chi-square and fisher exact test were used to measure the degree of association between the variable of interest. We have further used the linear regression method modeling the relationship between dependent variable and independent variables. Main dependent variables are interpretation of TORCH IgG and TORCH IgM index. While independent variables are: abortions, intrauterine death, premature labor, microcephalus, low birth weight, congenital disease of new born. Level of significance was $5 \%$ meaning a $p$-value $<0.05$ was considered significant. We did not take TORCH IgM data due to undetectable results and CMV IgG due to $100 \%$ positive titers.

Ethical considerations. The study was ethically approved by the Research Ethics Committee, College of Medicine, King Khalid University, Riyadh, KSA (REC\# 2017-05-24).

Results. The mean age among the 190 antenatal cases was $31.4 \pm 6.5$ years, and the mean gestational age was $32.4 \pm 6.2$ weeks. Demographic data has been illustrated in Table 1. The seroprevalence of TORCH infections among pregnant women is illustrated

Table 1 - Demographic information $(n=190)$.

\begin{tabular}{lc}
\hline Variables & $\mathbf{n}(\%)$ \\
\hline Mean age of women (mean \pm SD) & $31.53 \pm 6.190$ \\
Gestational age at the time of sample collection & \\
$2^{\text {nd }}$ trimester $(13-28$ weeks) & $44(23)$ \\
$3^{\text {rd }}$ trimester $(29-40$ weeks) & $146(77)$ \\
Number of previous pregnancies & \\
$1-2$ pregnancies & $112(59)$ \\
3 and more pregnancies & $78(41)$ \\
\hline
\end{tabular}

Table 2 - Seroprevalence of toxoplasmosis, rubella, cytomegalovirus, and herpes infections among pregnant women $(\mathrm{n}=190)$.

\begin{tabular}{lccrrr}
\hline Variables & \multicolumn{3}{c}{ Immunoglobulin G } & \multicolumn{3}{c}{ Immunoglobulin M } \\
& Positive & Negative & Positive & Negative \\
\hline Toxoplasma gondii & $52(27.4)$ & $138(72.6)$ & 0 & $190(100)$ \\
HSV-1 & $180(94.7)$ & 10 & $(5.3)$ & 0 & $190(100)$ \\
HSV-2 & 1 & $(0.5)$ & $189(99.5)$ & 0 & $190(100)$ \\
CMV & $190(100)$ & 0 & $18(9.5)$ & $172(90.5)$ \\
Rubella & $169(88.9)$ & $21(11.1)$ & 0 & $190(100)$ \\
\hline \multicolumn{5}{c}{ Values are presented as number and percentage (\%). } \\
\multicolumn{5}{c}{ HSV-1: herpes simplex type 1, HSV-2: herpes simplex type 2, } \\
CMV: cytomegalovirus virus
\end{tabular}




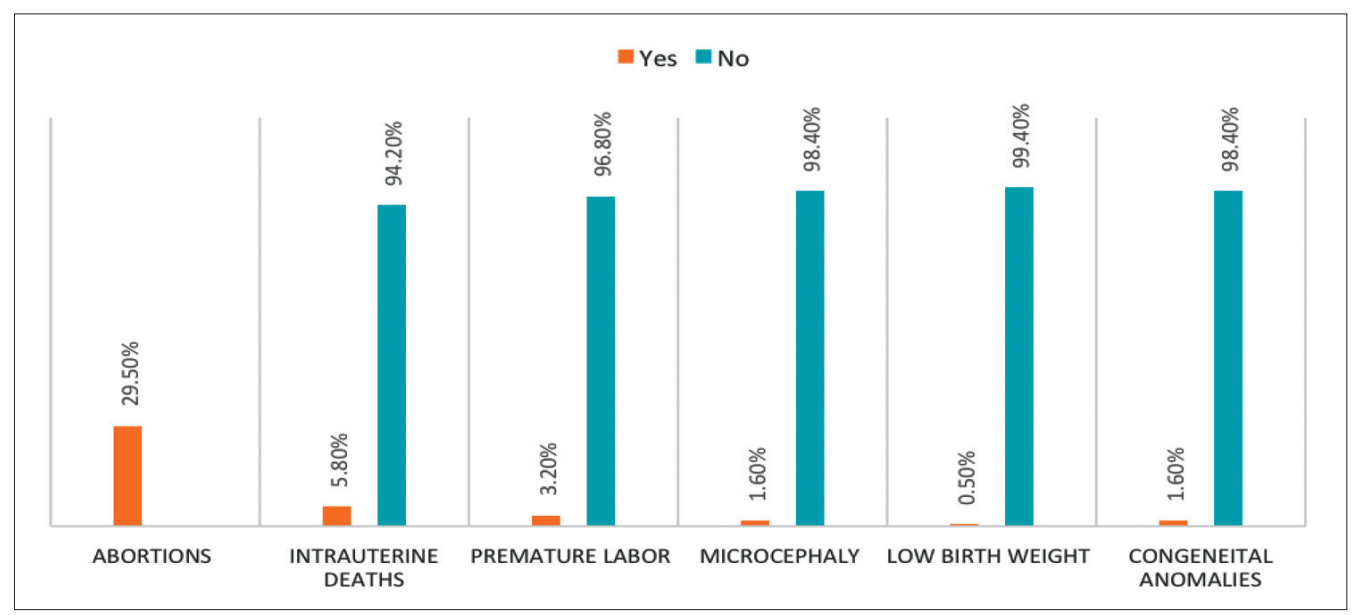

Figure 1 - Frequency of previous pregnancy outcomes.

in Table 2. Approximately $27.4 \%$ were positive for T. gondii IgG, $94.7 \%$ were positive for HSV-1 IgG, $0.5 \%$ were positive for HSV-2 IgG, $100 \%$ were positive for CMV IgG, and $88.9 \%$ were positive for rubella IgG. We observed $9.5 \%$ positivity for CMV IgM, while all other TORCH IgMs were negative or undetectable.

In this study, the relevant clinical associations with TORCH positive antenatal cases included premature labor, low birth weight, IUD abortions, microcephaly, and other congenital malformations observed in babies, as illustrated in Figure 1. The highest rate of abortions was found among women with previous pregnancies, followed by women with past IUDs, premature labor , women with microcephalic babies, congenital diseases, and low birth weight; however, these observations were not statically significant.

The association of TORCH IgG positivity with previous pregnancy outcomes were subjected to univariate and multivariate logistic regression as possible predication matrix illustrated in Table 3.

$P$-values were not found to be statistically significant at $5 \%$ among any of the variables and were not calculated for CMV IgG, and IgM as the former was positive for $100 \%$ of cases while the latter did not include any follow-ups to check with birth anomalies.

Discussion. The results of our study were in agreement with birth anomalies due to infections outlined in the TORCH panel. The association between infection and clinical condition was first examined in the context of gestational and mean age for all antenatal cases. The results demonstrated a strong impact of TORCH infections on birth anomalies at higher ages, thus in agreement with previously published studies demonstrating an increase in the incidence of TORCH infections among pregnant women in the age group >30.9. A study conducted in China reported severe pregnancy outcomes in patients infected with TORCH, including congenital malformations (12.9\%), abortions $(31.8 \%)$, premature labor $(8.2 \%)$, and infant death (9.4\%). ${ }^{10}$ Although the present study did not report any infant deaths, abortion rates were high and congenital malformations as well as premature labor were low. We also observed microcephaly and low birth weights, in contrast to the above study. All antenatal cases were positive for at least one TORCH organism such as $\mathrm{CMV}$, indicating past infection.

Previous studies from KSA showed a varied exposure pattern of one or 2 of the TORCH organisms among pregnant women and the general population. A study carried out in the Jizan province of KSA showed 93.1\% positivity of CMV IgG among pregnant women, in similarity with our observations. ${ }^{9}$ Another report from Al Khobar, KSA, concerning HSV-1 and HSV-2 reported high seroprevalence of HSV-1 IgG antibodies $(93.2 \%)$, which is close to our results. However, the prevalence of HSV-2 was much higher $(54.7 \%)$ than that reported in the present study. ${ }^{11}$ However, similar to our results, the Al Khobar study did not report HSV IgM positivity, indicating a current infection. Previous studies have revealed that toxoplasmosis is common in the southern part of KSA, with T. gondii IgG antibodies at $29.2 \%$ and $T$. gondii IgM antibodies at $3.1 \%$, which are similar to the results of the present study. ${ }^{12}$ Recent studies on T. gondii from Makkah and Riyadh, KSA, reported T. gondii IgM positivity at $1.2 \%$ in Makkah 
positivity and around $6.4 \%$ in Riyadh. Toxoplasma gondii IgG positive patients had a history of premature labor, IUDs, and microcephaly, indicating that past infection with $T$. gondii could be a predictor of poor obstetric outcomes and congenital malformations, as in agreement with our observations. ${ }^{13}$ In the present study, results of CMV positivity (IgG and $\operatorname{IgM}$ )related complications, including abortions, congenital malformations, IUDs, preterm labor, microcephaly, and early neonatal mortality, were very similar to studies

Table 3 - Association of toxoplasmosis, rubella, cytomegalovirus, and herpes infections (TORCH) immunoglobulin G (IgG) positivity with previous pregnancy outcomes.

\begin{tabular}{|c|c|c|c|c|c|c|c|c|c|c|c|c|}
\hline \multirow[t]{2}{*}{ Variables } & \multicolumn{2}{|c|}{ Abortion } & \multicolumn{2}{|c|}{ Intrauterine death } & \multicolumn{2}{|c|}{ Premature labor } & \multicolumn{2}{|c|}{ Microcephaly } & \multicolumn{2}{|c|}{ Low birth weight } & \multicolumn{2}{|c|}{ Congenital disease } \\
\hline & No & Yes & No & Yes & No & Yes & No & Yes & No & Yes & No & Yes \\
\hline \multicolumn{13}{|c|}{ Toxoplasma gondii } \\
\hline Positive & $33(63.5)$ & $19(36.5)$ & $51(98.1)$ & $1(1.9)$ & $50(96.2)$ & $2(3.8)$ & $50(96.2)$ & $2(3.8)$ & $52(100)$ & 0 & $51(98.1)$ & $1(1.9)$ \\
\hline Negative & $101(73.2)$ & $37(26.8)$ & $128(92.8)$ & $10(7.2)$ & $134(97.1)$ & $4(2.9)$ & 137 (99.3) & $1(0.7)$ & $137(99.3)$ & $1(0.7)$ & $136(98.6)$ & $2(1.4)$ \\
\hline$P$-value ${ }^{*}$ & \multicolumn{2}{|c|}{0.190} & \multicolumn{2}{|c|}{0.161} & \multicolumn{2}{|c|}{0.739} & \multicolumn{2}{|c|}{0.124} & \multicolumn{2}{|c|}{0.538} & \multicolumn{2}{|c|}{0.815} \\
\hline $\begin{array}{l}\text { Univariate } \\
p \text {-value }{ }^{\dagger}\end{array}$ & \multicolumn{2}{|c|}{0.603} & \multicolumn{2}{|c|}{0.270} & \multicolumn{2}{|l|}{0.969} & \multicolumn{2}{|c|}{0.401} & \multicolumn{2}{|c|}{0.588} & \multicolumn{2}{|c|}{ ND } \\
\hline $\begin{array}{l}\text { Multivariate } \\
p \text {-value }\end{array}$ & \multicolumn{2}{|c|}{0.446} & \multicolumn{2}{|c|}{0.106} & \multicolumn{2}{|l|}{0.693} & \multicolumn{2}{|c|}{0.682} & \multicolumn{2}{|c|}{0.581} & \multicolumn{2}{|c|}{0.961} \\
\hline \multicolumn{13}{|c|}{ Herpes simplex type 1} \\
\hline Positive & $127(70.6)$ & $53(29.4)$ & $169(93.9)$ & $11(6.1)$ & $174(96.7)$ & $6(3.3)$ & $177(98.3)$ & $3(1.7)$ & $179(99.4)$ & $1(0.6)$ & $177(98.3)$ & $3(1.7)$ \\
\hline Negative & $7(70.0)$ & $3(30.0)$ & $10(100)$ & 0 & $10(100)$ & 0 & $10(100)$ & 0 & $10(100)$ & 0 & $10(100)$ & 0 \\
\hline$P$-value ${ }^{*}$ & 0.97 & & 0.42 & & 0.557 & & 0.681 & & 0.813 & & 0.68 & \\
\hline $\begin{array}{l}\text { Univariate } \\
p \text {-value }{ }^{\dagger}\end{array}$ & 0.98 & & 0.92 & & 0.870 & & 0.983 & & 0.838 & & ND & \\
\hline $\begin{array}{l}\text { Multivariate } \\
p \text {-value }\end{array}$ & 0.6 & & 0.66 & & 0.608 & & 0.733 & & 0.830 & & 0.80 & \\
\hline Herpes simplex $t$ & ype 2 & & & & & & & & & & & \\
\hline $\begin{array}{l}\text { Positive } \\
\text { Negative }\end{array}$ & $\begin{array}{r}1(100) \\
133(70.4)\end{array}$ & $\begin{array}{r}0 \\
56(29.6)\end{array}$ & $\begin{array}{r}1(100) \\
178(94.2)\end{array}$ & $\begin{array}{r}0 \\
11(5.8)\end{array}$ & $\begin{array}{r}1(100) \\
183(96.8)\end{array}$ & $\begin{array}{r}0 \\
6(3.2)\end{array}$ & $\begin{array}{r}1(100) \\
186(98.4)\end{array}$ & $\begin{array}{r}0 \\
3(1.6)\end{array}$ & $\begin{array}{r}1(100) \\
188(99.5)\end{array}$ & $\begin{array}{r}0 \\
1(0.5)\end{array}$ & $\begin{array}{r}1(100) \\
186(98.4)\end{array}$ & $\begin{array}{r}0 \\
3(1.6)\end{array}$ \\
\hline$P$-value ${ }^{*}$ & 0.5 & & 0.80 & & 0.856 & & 0.899 & & 0.942 & & 0.89 & \\
\hline $\begin{array}{l}\text { Univariate } \\
p \text {-value }\end{array}$ & 1.00 & & 0.99 & & 0.930 & & 0.995 & & 0.913 & & ND & \\
\hline $\begin{array}{l}\text { Multivariate } \\
p \text {-value }\end{array}$ & 0.62 & & 0.63 & & 0.967 & & 0.981 & & 0.965 & & 0.95 & \\
\hline Cytomegalovirus & & & & & & & & & & & & \\
\hline $\begin{array}{l}\text { Positive } \\
\text { Negative }\end{array}$ & $134(70.5)$ & $56(29.5)$ & $179(94.4)$ & $11(5.8)$ & $184(96.8)$ & $6(3.2)$ & $187(98.4)$ & $3(1.6)$ & $189(99.5)$ & $1(0.5)$ & $187(98.4)$ & $3(1.6)$ \\
\hline$P$-value ${ }^{*}$ & 0 & 0 & 0 & 0 & 0 & 0 & 0 & 0 & 0 & 0 & 0 & 0 \\
\hline $\begin{array}{l}\text { Univariate } \\
p \text {-value }\end{array}$ & - & & - & & - & & - & & - & & - & \\
\hline $\begin{array}{l}\text { Multivariate } \\
p \text {-value } \mathrm{e}^{\ddagger}\end{array}$ & - & & - & & - & & - & & - & & - & \\
\hline $\begin{array}{l}\text { Multivariate } \\
p \text {-value } \text { f }^{\ddagger}\end{array}$ & - & & - & & - & & - & & - & & - & \\
\hline Rubella & & & & & & & & & & & & \\
\hline Positive & $116(68.6)$ & $53(31.4)$ & $159(94.1)$ & $10(5.9)$ & $164(97.0)$ & $5(3.0)$ & $166(98.2)$ & $3(1.8)$ & $168(99.4)$ & $1(0.6)$ & $167(98.8)$ & $2(1.2)$ \\
\hline Negative & $18(85.7)$ & $3(14.3)$ & $20(95.2)$ & $1(4.8)$ & $20(95.2)$ & $1(4.8)$ & $21(100)$ & 0 & $21(100)$ & 0 & $20(95.2)$ & $1(4.8)$ \\
\hline$P$-value ${ }^{*}$ & 0.1 & & 0.83 & & 0.656 & & 0.538 & & 0.724 & & 0.21 & \\
\hline $\begin{array}{l}\text { Univariate } \\
p \text {-value }{ }^{\dagger}\end{array}$ & 0.82 & & 0.24 & & 0.375 & & 0.98 & & 0.851 & & ND & \\
\hline $\begin{array}{l}\text { Multivariate } \\
p \text {-value }{ }^{\ddagger}\end{array}$ & $0.2 c$ & & 0.90 & & 0.912 & & 0.50 & & 0.833 & & 0.19 & \\
\hline
\end{tabular}


reporting a high incidence of abortion, premature delivery and stillbirths associated with high rates of CMV seropositivity. ${ }^{5}$

Little has changed regarding the TORCH status and has remained unaltered for more than a decade, as evidenced from a study conducted in Makkah, KSA, in 2002. The present study shows IgG antibodies to $T$. gondii at $27.4 \%$, compared to $35.6 \%$ in the Makkah study. Furthermore, the antibody prevalence of CMV IgG (92.1\%), rubella IgG (93.3\%), HSV-1 IgG (90.9\%) and HSV-2 IgG (27.1\%) were slightly low compared with the present study, with the exception of HSV-2. ${ }^{14}$

Our results showing high IgG rubella positivity are corroborated by the results of premature labor, IUDs, low birth weight and congenital malformations (wherever information was available), and were in good agreement with previously published studies. ${ }^{14}$ Immunoglobulin $\mathrm{G}$ levels for rubella clearly indicate the success of the 1982 combined vaccination policy against rubella in KSA. However, the increase in poor obstetric outcomes and congenital anomalies (not specific for rubella) needs further investigation. ${ }^{15}$

These results clearly suggest that the prevalence of TORCH agents remains high in KSA and can contribute to various congenital infections and other complications. Periodic screening for antenatal mothers thus becomes necessary to avoid TORCH complications, which results in pregnancy-related and neonatal morbidity.

Study limitations. Our study demonstrated an association between IgG antibody positivity of the TORCH panel with previous pregnancy outcomes such as IUDs, abortions, premature labor, congenital malformations, microcephaly, and low birth weights; however, the lack of a higher sample size limited us in obtaining a statistically significant correlation. Further, very few studies are available from this part of KSA, and we, as authors, believe that our results are only part of the larger picture of TORCH infections and their complications, which warrant further investigation.

In conclusion, it is evident that there is an association between TORCH infections and pregnancy-related complications from our observations in the Abha region, KSA. Past infections, as reported here, warrant an independent study in female populations post-puberty. We were also able to link pregnancy outcomes with the TORCH panel results of the study group, indicating the sustained presence of TORCH infections that are prevalent in these regions. Additionally, these results clearly highlight the need for additional multicenter studies as well as therapeutic and management plans to address the burden of TORCH infections, especially CMV in our case.

Acknowledgment. The authors would like to thank the Deanship of Scientific Research, King Khalid University, for funding the research (Project \# 434/1439). The authors is also gratefully acknowledged Mr. Muhammad Abid, Department of Medical Education, College of Medicine, King Khalid University, Abha, Kingdom of Saudi Arabia for his statistical guidance and help in the data analysis.

Received 25th January 2020. Accepted 13th March 2020.

From the Department of Microbiology and Clinical Parasitology (Al-Hakami, Paul, Moosa, Chandramoorthy); from the Department of Child Health (Shati); from the Department of Family and Community Medicine (Riaz); from College of Medicine (Assiri, Qasim), King Khalid University, from the Department of Main Laboratory (Al-Abed); and from the Department of Neonatology (Alzoani), Abha Maternity and Children Hospital, Ministry of Health, Abha, Kingdom of Saudi Arabia.

Address correspondence and reprints request to: Dr. Ahmed M. Al-Hakami, Department of Microbiology and Clinical Parasitology, College of Medicine, King Khalid University, Abha, Kingdom of Saudi Arabia.E-mail:amhakami@gmail.com

ORCID ID: https://orcid.org/0000-0003-3938-5182

\section{References}

1. Zeb MA, Jamal SF, Mir A, Khan AA. Frequency of TORCH infections during pregnancy in Peshawar, Pakistan. Advances in Applied Science Research 2018; 9: 22-26.

2. Das S, Ramachandran VG, Arora R. Cytomegalovirus and rubella infection in children and pregnant mothers--a hospital based study. J Commun Dis 2007; 39: 113-117.

3. El-Tantawy N, Taman A, Shalaby H. Toxoplasmosis and female infertility: Is there a co-relation? Am J Epidemiol Infect Dis 2014; 2: 29-32.

4. Sadik MS, Fatima H, Jamil K, Patil C. Study of TORCH profile in patients with bad obstetric history. Biol Med 2012; 4: 95-101.

5. Revello MG, Tibaldi C, Masuelli G, Frisina V, Sacchi A, Furione $\mathrm{M}$, et al. Prevention of primary cytomegalovirus infection in pregnancy. EBioMedicine 2015; 2: 1205-1210.

6. Ghazi HO, Telmesani AM, Mahomed MF. TORCH agents in pregnant Saudi women. Med Princ Pract 2002; 11: 180-182.

7. Kesson AM. Management of neonatal herpes simplex virus infection. Paediatr Drugs 2001; 3: 81-90.

8. Sirin MC, Agus N, Yilmaz N, Bayram A, Derici YK, Samlioglu $\mathrm{P}$, et al. Seroprevalence of toxoplasma gondii, rubella virus and cytomegalovirus among pregnant women and the importance of avidity assays. Saudi Med J 2017; 38: 727-732.

9. Bakri M, Agag A, Alnemri A, Hobani Y, Najmi A, Alaamri AI, et al. Serostatus of cytomegalovirus among population, Jazan region, Saudi Arabia. Sociology Job Market Rumors 2016; 4: 52-59. 
10. Wang Y, Li S, Ma N, Zhang Q, Wang H, Cui J, et al. The association of ToRCH infection and congenital malformations: A prospective study in China. Eur J Obstet Gynecol Reprod Biol 2019; 240: 336-340.

11. Obeid OE. Prevalence of herpes simplex virus types 1 and 2 and associated sociodemographic variables in pregnant women attending King Fahd hospital of the university. J Family Community Med 2007; 14: 3-7.

12. El-Shahawy IS, Khalil MI, Bahnass MM. Seroprevalence of toxoplasma gondii in women in Najran City, Saudi Arabia. Saudi Med J 2014; 35: 1143-1146.
13. Alghamdi J, Elamin MH, Alhabib S. Prevalence and genotyping of toxoplasma gondii among Saudi pregnant women in Saudi Arabia. Saudi Pharm J 2016; 24: 645-651.

14. Alsibiani SA. Rubella immunity among pregnant women in Jeddah, Western Region of Saudi Arabia. Obstet Gynecol Int 2014; 2014: 659838.

15. Wilson-Davies ESW, Aitken C. When should the "TORCH" study be requested? Paediatr Child Health 2013; 23: 226-228. 